\title{
O CULTIVO AGRÍCOLA COMO AGENTE INTENSIFICADOR DA DEGRADAÇÃO AMBIENTAL EM UMA ÁREA DE MICROBACIA DO ARROIO PORTELA, NO MUNICÍPIO DE NOVA PALMA/RS ${ }^{1}$
}

\author{
AGRICULTURAL CULTIVATION AS AN INTENSIFYING AGENT FOR \\ ENVIRONMENTAL DEGRADATION IN A MICROBACIA AREA OF \\ ARROIO PORTELA, IN THE MUNICIPALITY OF NOVA PALMA / RS.
}

\section{Gabriela Piovesan², Valdemar Valente ${ }^{3}$, Carla Maria de Pelegrin ${ }^{4}$ e Ana Paula Rodrigues ${ }^{5}$}

\section{RESUMO}

O setor agropecuário está cada vez mais agregando novas áreas de cultivo para satisfazer as necessidades produtivas e do mercado econômico. Áreas que antes eram campos e florestas, atualmente estão sendo substituídas por espaços cultivados. Com o intuito de discutir essa temática, o presente trabalho objetivou analisar a evolução do uso da terra através de imagens de satélites em uma área de microbacia no município de Nova Palma/RS, considerando os anos de 2008 e 2019. O estudo também buscou avaliar os impactos ambientais, especialmente no solo e recursos hídricos devido a evolução no setor agrícola no local de estudo. Na metodologia, foram usadas fontes de informações do tipo bibliográfica e digital, seguindo critérios analíticos por meio do sequenciamento dedutivo de ideias, ou seja, partindo-se de uma abordagem geral para uma visão particular. Na sequência, foram confeccionados mapas da área de estudos e capturado imagens dos pontos de maior relevância para a pesquisa. Os resultados comprovaram que houve um aumento das áreas de uso agrícola, com a consequente diminuição das áreas de campo na proporção de $13 \%$. Também foi percebido um pequeno aumento nas áreas de florestas, porém isso se deve a substituição desta vegetação por espécies não nativas. Percebeu-se ainda uma expressiva diminuição no percentual da taxa de corpos hídricos, fato esse que provoca grande apreensão, pois cada vez mais se prima pela presença e qualidade da água.

Palavras-chave: Atividade agrícola, Meio ambiente, Uso da terra.

\section{ABSTRACT}

The agricultural sector is increasingly adding new cultivated areas to meet production and economic market needs. Areas that were once fields and forests are currently being replaced by cultivated spaces. In order to discuss this theme, the present work aimed to analyze the evolution of land use through satellite images in a watershed area in the municipality of Nova Palma/RS, considering the years 2008 and 2019. The study also sought to evaluate the environmental impacts, especially on soil and water resources due to the evolution in the agricultural sector in the study site. In the methodology, bibliographic and digital sources of information were used, following analytical criteria through the deductive sequencing of ideas, that is, starting from a general approach to a particular view. In the sequence, maps of the study area were made and images of the most relevant points for the research were captured. The results showed that there was an increase in the areas

1 Trabalho realizado como pré-requisito para conclusão do curso de Pós-Graduação em Geografia, Meio Ambiente e Sustentabilidade pela faculdade Futura/SP.

2 Licenciada em Geografia e Pós-graduada no curso de Geografia, Meio Ambiente e Sustentabilidade. E-mail: gabispiovesan@ gmail.com

3 Coorientador. E-mail: vvalente_unifra@yahoo.com.br

4 Coorientadora. E-mail: carla.pelegrin@uffs.edu.br

5 Orientadora. E-mail: contato@faculdadefutura.com.br 
under agricultural use, with a consequent decrease in field areas of 13\%. A small increase in forest areas was also noticed, but this is due to the replacement of this vegetation by non-native species. It was also noticed a significant decrease in the percentage of water bodies, a fact that causes great apprehension, because the presence and quality of water is increasingly important.

Keywords: Agricultural activity, Environment, Land use.

\section{INTRODUÇÃO}

A produção e a produtividade agrícola brasileira tem alcançado patamares quantitativos significativos, devido ao modelo desenvolvimentista, implantado no país desde o período do regime militar, um modelo que busca o lucro, a disputa por matérias-primas e recursos naturais para satisfazer o mercado consumidor e industrial. Esse modelo econômico tem causado o uso indiscriminado e crescente expropriação dos recursos naturais nos países em desenvolvimento e, em especial, no Brasil.

A exemplo disso tivemos a política de extração e posterior exportação de matéria-prima, primeiramente pelo extrativismo de produtos naturais (pau-brasil), produtos oriundos do subsolo (minérios), e após, partiu-se para um modelo de extrativismo agrícola (café e cana de açúcar). Como consequência, a monocultura passa a predominar nas paisagens rurais brasileiras com a finalidade de abastecer os centros urbanos do país e do exterior, sobretudo países hegemônicos, para fins de satisfazer seus estilos de vida consumistas, como afirma Gonçalves (2012).

Com o advento da Revolução Verde, novas técnicas agrícolas e sementes com genética avançada, impulsionaram ainda mais a produção agrícola no país e vem se incorporando gradativamente no espaço geográfico brasileiro despontando com elevados níveis de produção, com ênfase à atividade da monocultura da soja e com destaque para a produção de exportação (BRUM, 1988).

Ocorre então a expansão da atividade agropecuária com a intensificação do uso de agrotóxicos, fertilizantes e corretivos; irrigação sem controle; monocultura em grande escala; uso inadequado de fatores de produção, enfatizando o emprego de alta tecnologia química e pesada mecanização. E por conta de todo esse investimento se fez necessário a utilização de grandes áreas cultivadas, pois

“[...] monoculturas em pequena escala não conseguem bancar o custo de atualizar a tecnologia agrícola e o equipamento necessário [...]" (BATISTA et al., 2018, p. 50), de modo a responder economicamente ao capital aplicado, como no caso do cultivo da soja.

Neste sentido, a monocultura, peça chave deste sistema, se destaca como um agroecossistema simplificado, homogeneizado e padronizado, no qual os complexos produtivos regem os destinos dos espaços rurais (SILVA, 2011). Estes sistemas apresentam-se indiretamente atrelados as corporações internacionais que regem os meios tanto de produção como de destinação dos produtos, seguindo sempre um modo fechado de produção com metas a serem cumpridas. 
Nesta perspectiva, a atividade agrícola no Brasil e, em especial no Rio Grande do Sul, vem ano após ano alcançando níveis expressivos em termos de produção e produtividade, de modo especial o cultivo de soja. A estimativa de produção para o Rio Grande do Sul da EMATER/RS - ASCAR (2019) para a safra de soja 2019/2020, indicava uma área de 5.956 .504 hectares, um aumento de 1,93\% em relação à safra anterior e uma produtividade estimada de 19.746.793 de toneladas, entretanto a estiagem frustrou a expectativa de produtividade na região.

Como já apresentado, esse aumento da produção agrícola, também se dá em detrimento do aumento da área de cultivo, utilizando além de outras técnicas, o uso intensivo do solo, mediante ao emprego da mecanização intensiva, representando uma industrialização da agricultura, pelo uso capitalista da terra, como indica Ross (1995), contribuindo para a concentração fundiária e provocando impactos que são mais potencializados quando a atividade agrícola é realizada em área com declividade acentuada e sobre microbacias hidrográficas com relevo irregular.

O presente estudo objetivou demonstrar a evolução da atividade agrícola por meio da confecção de mapas de uso e cobertura da terra e analisar as consequências desta evolução para o ambiente na área citada, ou seja, na microbacia do Arroio Portela, no município de Nova Palma/RS.

Neste sentido, o estudo faz-se importante, pois visa auxiliar na ampliação das discussões quanto a necessidade de se fazer o uso consciente dos recursos naturais, especialmente o solo, a água e a biodiversidade associada.

A elaboração deste artigo se deu por meio de revisão bibliográfica referente a estudos que permeiam a agricultura no Brasil e as consequências da modernização agrícola para com o meio ambiente. Como atividade concreta foram confeccionados mapas de uso da terra referente ao ano de 2008 e 2019 e, por meio destes, obteve-se a percepção da evolução da atividade agrícola na área de estudo, neste período.

\section{IMPACTOS AMBIENTAIS DA ATIVIDADE AGRÍCOLA.}

A estrutura do solo em áreas agricultáveis, de modo geral, está muito degradada, consequência da forma do uso da terra, que tem provocado o empobrecimento e esgotamento físico do solo. Conforme Silva e Barros (2003), apesar do solo e da água serem os dois recursos naturais principais para a sobrevivência da vida humana na Terra, o homem pouco ou nada cuida destes recursos, pois o processo de degradação do solo tem como causa o uso e manejo incorreto do mesmo, e a inobservância das particularidades físico-químicas e especificidades do relevo.

De acordo com Araujo, Almeida e Guerra (2005), os problemas que o uso indiscriminado do solo pode provocar à natureza são: o desmatamento, quando se usa a terra para a agricultura e pastagens; a compactação dos solos, quando houver grandes demandas de gado sobre a área ou o uso de máquinas excessivamente pesadas; o manejo inadequado da terra, quando se usa muitos agrotóxicos e a perda de solo pela erosão. 
Dechen et al. (2015) menciona que em alguns estudos estimam-se para o Brasil perdas de 616,5 milhões de toneladas de terra ao ano, decorrentes do processo de erosão do solo em lavouras, e custos da ordem de US\$1,3 bilhão ao ano, conforme pode ser observado na Tabela 1.

Tabela 1 - Cobertura e perda de solo em $\mathrm{Kg} / \mathrm{ha}$.

\begin{tabular}{|cc|}
\hline Tipo de cobertura & Perda de solo por eroção em $\mathbf{k g} / \mathbf{h a}$. ano \\
\hline Mata nativa & 4 \\
\hline Reflorestamento & 40 \\
\hline Pastagem & 400 \\
Café & 900 \\
Soja & 20.100 \\
\hline Algodão & 26.600 \\
\hline
\end{tabular}

Fonte: BERTONI et al., 1982 apud CAMPOS e FURTADO 2008, p. 17

Andrade (1997) afirma que em solos desflorestados com declividade baixa, de até 25\%, a massa sedimentar que atinge os vales e planícies que cortam as encostas, intensifica o entulhamento dos canais flúvicos, tanto dos grandes rios, como também de regatos e veredas. Contudo, quando essa análise é realizada em solos com declividade mais elevada e desflorestado, esse processo é muito mais expressivo.

Essas práticas se intensificam mais notoriamente em relação às formas inadequadas de manejo de solo e ao modelo agrícola mundial, que em nada contribuem com a sustentabilidade, priorizando práticas que são prejudiciais ao meio ambiente como a monocultura em grandes áreas. Nota-se que esta realidade deriva de um modelo de desenvolvimento agrícola que foi imposto ao país e está muito atuante na atualidade, como destaca Campos e Tsukamoto (2003) apud Dallanora e Valente (2014).

A prática da agricultura moderna no país, assim como no mundo, vem ocasionando a diminuição da biodiversidade, devido à intensificação no uso de máquinas agrícolas e insumos químicos em ambientes frágeis, ocasionando danos irreversíveis para o sistema ambiental. Nesta mesma lógica de pensamento, Leff (2002) constata que a degradação do ambiente está vinculada ao projeto civilizatório atual, e que somente o agir sustentável levaria ao equilíbrio ecológico e social, de forma a oportunizar melhores condições ambientais para as atuais e futuras gerações.

\section{O BIOMA E OS RECURSOS HÍDRICOS EM ÁREAS COM USO AGRÍCOLA INTENSIVO}

As bacias hidrográficas são paisagens ou unidades ambientais, onde ocorre a inter-relação entre elementos naturais e humanos de maneira efetiva e inseparável. Estes locais refletem a atividade humana diretamente no sistema aquático, que é o espelho do que acontece na região, nesse entendimento compreende-se que:

As atividades agrícolas têm gerados prejuízos ao meio ambiente afetando o solo, as águas, a fauna e flora. A agricultura causa danos irreversíveis ao solo, tornando terras que antes eram férteis em terras inapropriadas para o uso, além de milhões de litros de água que são utilizados para essa atividade. (LAGE, 2017, p. 02). 
A atividade agrícola por si só não é o único meio de contaminação dos mananciais hídricos, mas contribui e muito para a degradação da qualidade das águas de uma maneira geral. O uso e manejo inadequado do solo em bacias hidrográficas, especialmente quando ocorre a aplicação de insumos químicos tem provocado a contaminação dos recursos hídricos por substâncias orgânicas ou inorgânicas, naturais ou sintéticas e por agentes biológicos que são empregados de forma inadequada durante a utilização de defensivos e fertilizantes. (SOUZA; GHILARDI, 2017).

Durante as precipitações, a água percola sobre o solo, indo em direção as áreas mais baixas do terreno e ao encontro do rio principal da microbacia, levando consigo muitos sedimentos, dentre eles micropartículas de solo, rochas, micronutrientes e adubos que estavam presentes no solo. Furtado e Konig (2008) apontam que através do uso excessivo do solo para a prática agrícola, associado à falta de conservação das matas ciliares, se intensificam os processos de assoreamento e degradação do leito dos rios.

Como descreve Lage (2017), ainda associado aos problemas acima, está o uso de agrotóxicos de maneira inadequada, pois são produtos muito tóxicos, que deixam elevados teores de resíduos nos alimentos, bem como a alteração biológica do produto, a contaminação e degradação ambiental, intoxicação de seres vivos e mudança no comportamento e resistência de pragas à toxidade destes produtos.

A biodiversidade na agricultura é a base dos sistemas alimentares. Conforme relatório da FAO (2019), a "biodiversidade associada" é o conjunto de organismos que apoiam a produção de alimentos incluindo abelhas, insetos e outros polinizadores, plantas, animais como morcegos, pássaros e os microrganismos como fungos e bactérias que ajudam a purificar a água e o ar, combatem doenças agrícolas e pecuárias, mantendo os solos férteis e dando estabilidade ao ecossistema. Essa diversidade na produção agrícola engloba plantas e animais silvestres e domesticados, que fazem parte de uma cadeia ecológica que auxilia no combate às pragas e doenças de culturas agrícolas e animais.

O órgão federativo CONAMA (Conselho Nacional do Meio Ambiente) em sua primeira resolução caracteriza por Impacto Ambiental, qualquer alteração das propriedades físicas, químicas e biológicas do meio ambiente, resultante de atividades humanas (BRASIL, 1986). A esse pressuposto cabe qualquer atividade humana que venha a interferir direta ou indiretamente na saúde, segurança e no bem-estar da população, nas atividades sociais e econômicas, na biota, nas condições estéticas e sanitárias do meio ambiente e na qualidade dos recursos ambientais.

O PNMA, Política Nacional do Meio Ambiente, em seu artigo $4^{\circ}$, estabelece uma relação no desenvolvimento econômico e social com a preservação e equilíbrio ambiental (BRASIL, 1981). Neste sentido, é preciso estabelecer ações no âmbito político que prosperem com o crescimento econômico e na conservação do solo e gestão hídrica, enfatizando um desenvolvimento sustentável que permita a renovação dos recursos e preservação do solo, ar, águas e biodiversidade associada. 


\section{MATERIAIS E MÉTODOS}

O presente estudo desenvolveu-se através de pesquisa bibliográfica, seguindo critérios analíticos por meio do sequenciamento dedutivo de ideias, pois partiu de uma abordagem geral para uma visão particular. Na elaboração do trabalho foram realizadas coleta e análise de dados conforme descritos abaixo. Na confecção da base cartográfica, foi delimitada a área de estudo, com o auxílio de imagens de satélite ALOS e do seu sensor radar PALSAR de 12,5 metros de resolução espacial no qual aplicou-se técnicas de geoprocessamento a partir das ferramentas de análise hidrológica Arc Hydro no software ArcGIS 10.5.®(ESRI). Para o mapeamento, utilizou-se imagens dos satélites Landsat 5 TM (Thematic Mapper) de 18 de novembro de 2008 e Landsat 8 OLI (Operational Land Imager) de 25 de outubro de 2019, ambas com 30 metros de resolução espacial, sem cobertura de nuvens e em refletância de superfície. Em seguida, iniciou-se o processo de classificação digital de imagem em classes de uso e cobertura da terra: floresta, campo, agricultura, corpos hídricos e área urbana. A classificação digital foi supervisionada, pois foram realizadas visitas técnicas e trabalhos de campo na microbacia do Arroio Portela, permitindo assim, conhecer os principais tipos de usos e coberturas da terra. A partir do processamento e classificação digital de imagem, foi possível quantificar as diferentes classes, de uso e cobertura da terra. Os trabalhos de campo envolveram análise descritiva do uso do solo e documentação digitalizada através de imagens fotográficas capturadas em setembro de 2020.

\section{CARACTERIZAÇÃO DA ÁREA DE ESTUDO}

A área de estudo está situada sobre os domínios territoriais do município de Nova Palma/RS,

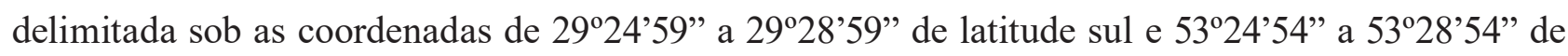
longitude oeste, a uma distância de cerca de $320 \mathrm{~km}$ da capital Porto Alegre, situada na região central do estado do Rio Grande do Sul. Em 2010 a população do município era de 6.342 habitantes (IBGE, 2020), e que têm na atividade agropecuária, indústria e comércio a sua base econômica.

O município de Nova Palma está localizado geomorfologicamente entre a Depressão Central e o Rebordo do Planalto da Serra Geral. O relevo apresenta aspectos topográficos de planaltos, serras e vales; a cobertura vegetal predominante é de áreas cultivadas, campos e matas nativas que vem sendo descaracterizados para dar lugar a implantação de área cultivada (PIOVESAN; AUSANI, 2011). O clima conforme a classificação de Köppen é do tipo temperado úmido com verões quentes que chegam a $22^{\circ} \mathrm{C}$ e $-3^{\circ} \mathrm{C}$ nos períodos mais frios, apresenta ocorrência de chuvas o ano todo (MORENO, 1961). O sistema hidrográfico pertence à bacia do Rio Jacuí da qual faz parte a sub-bacia do Rio Soturno (FACCO et al., 2016), de onde o Arroio Portela é seu afluente. A microbacia de estudo está disposta sobre uma área de 2.318,67 hectares, estabelecida em uma geomorfologia bastante irregular com presença de muitas encostas e cerros. 


\section{RESULTADOS}

A microbacia está localizada em uma área de transição entre o planalto e a depressão periférica, caracterizada pela presença de relevo por vezes plano e altimetria elevada, por vezes acidentado e com surgimento de escarpas, e com atividade agrícola bem consolidada, conforme Rossato (2010). Através da análise da Figura 1, é possível conhecer a estrutura física da área de estudo e poder ter um melhor entendimento da variação do uso da terra no período de 2008 e 2019.

Figura 1 - Mapa da Dinâmica do Uso e Cobertura da Terra de 2008-2019.

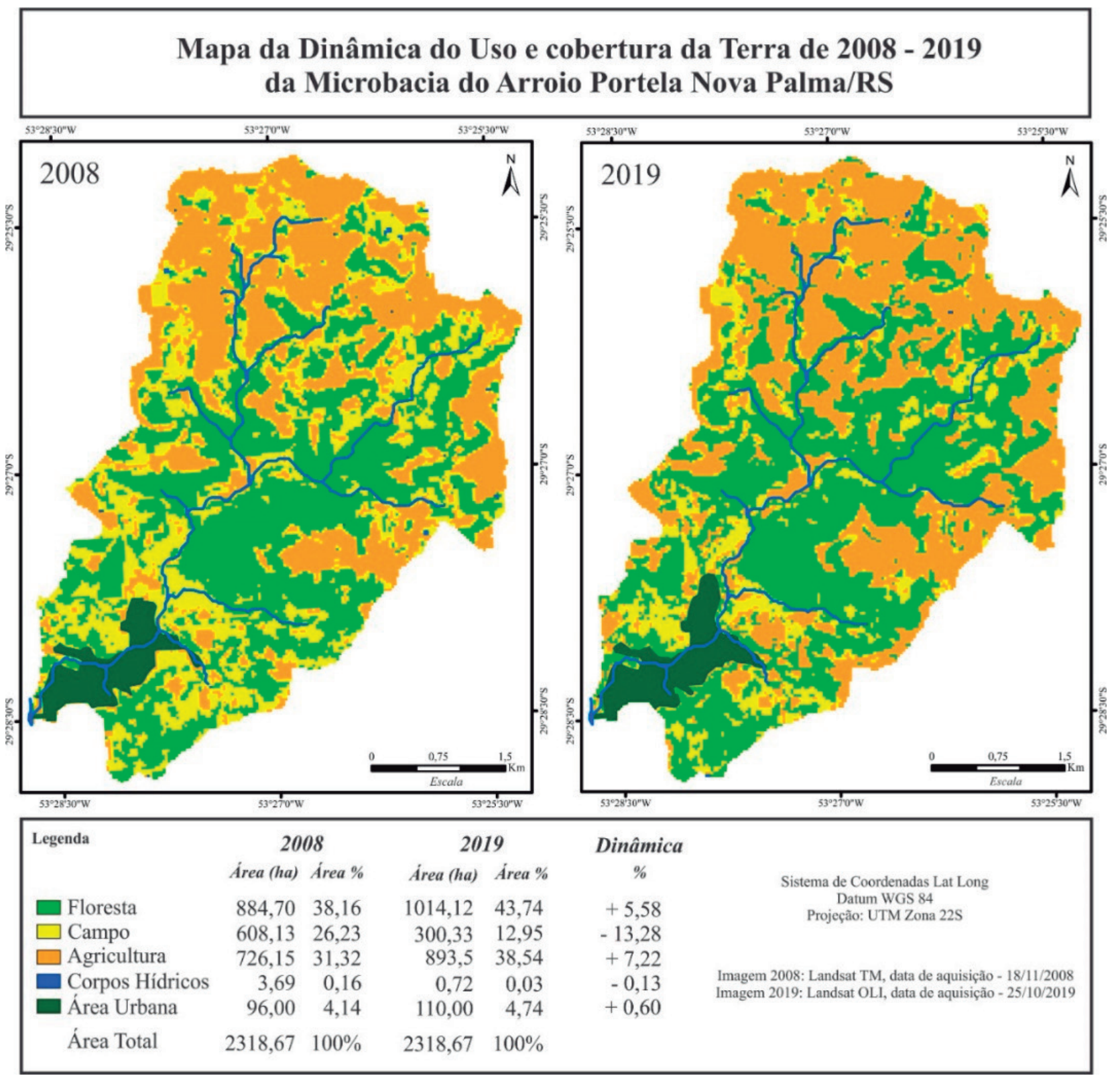

Fonte: Autora.

As imagens de satélites foram captadas nos meses de outubro/novembro, época em que começam os preparativos no solo para o próximo cultivo. Por meio da comparação entre os mapas foi 
possível perceber a elevação da área marcada como agrícola, crescimento já percebido anteriormente por Rossato (2010, p. 14), a qual mencionava que no município “[...] as áreas mais devastadas, coincidem com os topos dos morros e as várzeas dos rios [...]", coincidindo com os locais de maior uso agrícola.

Na comparação das imagens este aumento foi de 7\%, o que equivale a um agregado de cerca de 167 hectares de área cultivável quando comparado a evolução nos dois mapas, e se acentua especialmente na parte superior da microbacia, onde o relevo é mais plano e ocorrem as nascentes d'água.

O aumento da área cultivada se deu em detrimento da diminuição das áreas de campo, que tiveram uma perda de $13 \%$, o equivalente a uma diminuição de 307,8 hectares, quando comparados os mapas de 2008 e de 2019, comprovando o que já vem sendo exposto nesta pesquisa que é a destinação cada vez maior dos espaços cultiváveis para a implantação da atividade agrícola. Este aumento é consequência do modelo agrícola atual, como anteriormente mencionado por Batista et al. (2018), pois os agricultores se veem pressionados a aumentar a produção para recuperar o investimento na agricultura, ocupando todas as áreas que podem ser agricultáveis.

Com a substituição das áreas de campo por áreas de cultivo, a fauna e flora têm seu espaço natural de ocupação reduzido e modificado. Com a nova destinação de uso da terra ocorre o revolvimento e exposição do solo, ocasionando o seu empobrecimento pelo escoamento superficial de matéria orgânica (ZAMBERLAN, 2014), especialmente em relevos com declividade mais acentuadas como é destacado por Furtado e Konig (2008), cujo fator de gravidade em um solo com alta declividade e exposto, somado ao peso do volume hídrico, pode causar processos erosivos bem consideráveis, tornando o leito fluvial suscetível a receber toda carga de detritos do solo, assoreando-o (PIOVESAN; AUSANI, 2011), como pode ser visto na figura 2.

Outra questão que no decorrer deste estudo também é ressaltada, refere-se às áreas de cabeceiras desta microbacia, ou seja, áreas de nascentes, que em quase sua totalidade encontram-se desprovidas de matas ciliares, visto que nas áreas mais elevadas do relevo são também as mais planas, e é ali que a produção agrícola é mais intensificada de forma a utilizar todas as áreas possíveis para o cultivo, à medida que favorece o emprego de máquinas, desconsiderando, desta forma, o cuidado com a preservação das nascentes do arroio.

No entanto, algo que pode ser comemorado refere-se à área ocupada por florestas que teve uma expressiva elevação. Nota-se que um dos fatores deste aumento de $5 \%$ se deve a intensificação do manejo de espécies arbóreas exóticas ou não nativas, como é o caso do eucalipto que tem seu cultivo também usado para fins comerciais de madeira como pode ser visto nas figuras 3. Outro fator que auxiliou no aumento da área florestal no município foi o fato da legislação ambiental ser de fato cumprida no município, o que de certa forma impede o desflorestamento de áreas nativas e motiva o florestamento em áreas mais sensíveis como encostas e margens dos leitos d'água, como já foi descrito por Facco et al. (2018). 
Em relação à área urbana, observamos uma elevação considerável, ou seja, um aumento de 14 hectares de área com urbanização, mesmo sendo considerado município de pequeno porte. Tal fato se deve, em grande parte, a saída dos moradores das áreas rurais pela dificuldade em manter-se neste espaço, além de dificuldades para produzir, vindo a estabelecer-se nas áreas periféricas da cidade.

Por fim, o que tem causado uma grande apreensão refere-se aos corpos hídricos, que tiveram uma diminuição considerável de área percebida pelas imagens de satélites, chegando a uma redução de 2,97 hectares. Esse fato pode estar relacionado com a prática de fazer drenagens de áreas alagadas para uso agrícola e extinção de açudes e bebedouros, haja visto que esta redução da proporção hídrica reflete em defasagens em toda a estrutura de estabilidade de uma microbacia hidrográfica e dos sistemas ecológicos como um todo.

Figura 2 - Assoreamento no leito do Arroio Portela.

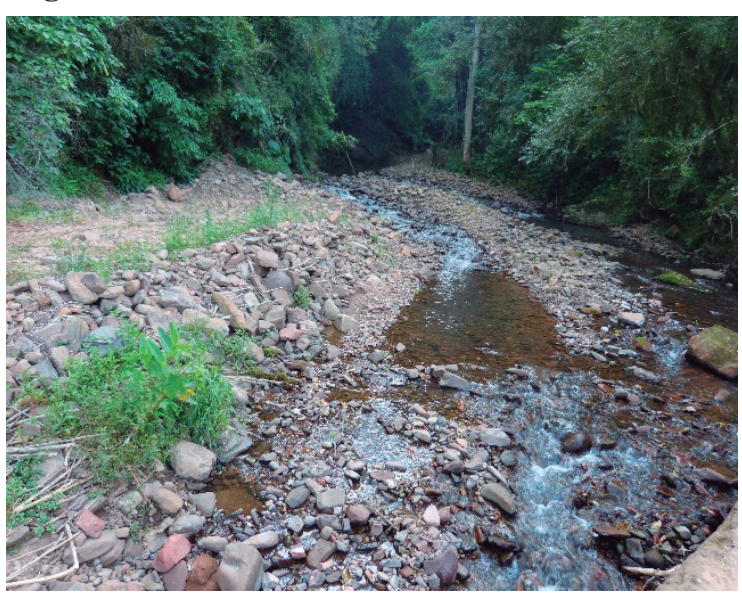

Fonte: Trabalho de campo, Setembro/2020.
Figura 3 - Reflorestamento com Eucaliptos

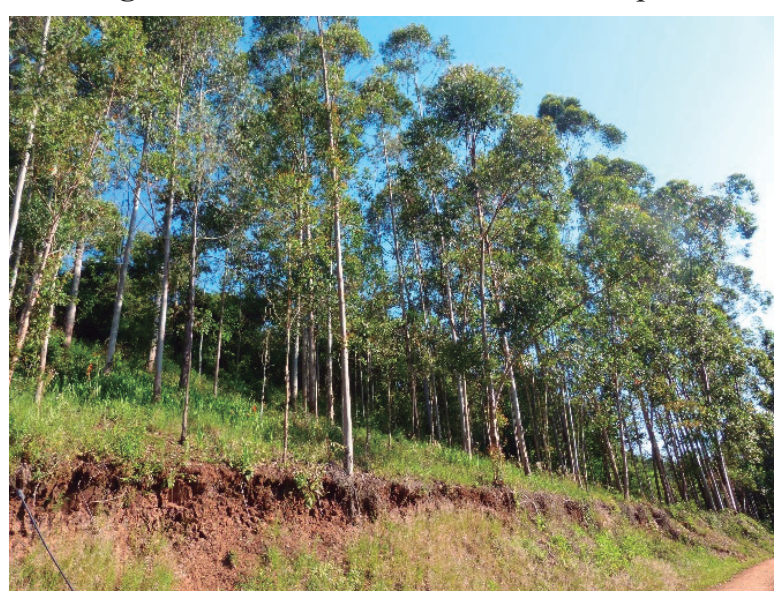

Fonte: Trabalho de campo, Setembro/2020.

\section{CONSIDERAÇÕES FINAIS}

O cultivo agrícola tem se intensificado no cenário rural do país, em especial a monocultura da soja, devido aos incentivos nas esferas governamentais e privadas. Desse modo, o agronegócio tem se tornado cada vez mais atrativo monetariamente, e atraindo muito mais produtores. Na região central do estado do Rio Grande do Sul, em especial na microbacia do Arroio Portela, município de Nova Palma, essa ação não é diferente do restante do país.

Através da análise dos mapas, foi possível visualizar a elevação considerável do uso da terra para fins de cultivo mecanizado, em detrimento da redução das áreas de campo nativo. Desta forma, o estudo comprovou a elevação da área destinada à atividade agrícola na microbacia em estudo no decorrer do período de análise, o que tem ocasionado o empobrecimento dos solos, através da lixiviação e o assoreamento nos canais hídricos. Os impactos são mais potencializados quando a atividade agrícola é realizada em área com declividade acentuada e sobre microbacias hidrográficas com relevo irregular, ocasionando uma considerável lixiviação do solo pelo escoamento de detritos pertencentes 
ao solo trabalhado pela agricultura, materiais orgânicos, produtos químicos e fertilizantes, indo estes depositar-se nas áreas mais baixas do relevo e no leito dos rios.

Essa intensificação da atividade agrícola, sem levar em conta os aspectos de ordem ambiental, tem causado problemas bem expressivos ao meio ambiente, como o desmatamento, pois é perceptível a falta de matas ciliares na borda do Arroio, o que agrava ainda mais os problemas referentes aos recursos hídricos, tornando-os eutrofizados e com grande carga de sedimentos em seu leito.

Dessa forma, acredita-se que os impactos sejam muito prejudiciais ao meio ambiente, especialmente com relação à diminuição da biodiversidade causada pelo desmatamento; má utilização do solo e introdução de espécies arbóreas não nativas.

\section{REFERÊNCIAS}

ANDRADE, M. C.de. A Geografia e a questão social. Recife: Edufal, 1997.

ARAUJO, G. H. de S.; ALMEIDA, J. R. de; GUERRA, A. J. T. Gestão ambiental de áreas degradadas. Rio de Janeiro: Bertrand Brasil, 2005.

BATISTA, et al. Adoção da Monocultura: o impacto econômico gerado em Santo Antônio de Lisboa - PI. In: ANDRADE, D.F. et al. (Orgs.). Tópicos em Administração. v. 12, Belo Horizonte - MG: Poisson, cap. 5, p. 48-61, 2018. Disponível em: https://bit.ly/3Ays1DK. Acesso em: 26 jul. 2020.

BERTONI, J.E.A., STUBBLEBINE, W.H., MARTINS, F.R. \& LEITÃO-FILHO, H. F. Nota prévia: comparação das principais espécies de florestas de terra firme e ciliar na Reserva Estadual de Porto Ferreira (SP). Anais do Congresso Nacional sobre Essências Nativas, Campos de Jordão. Silvic. São Paulo p. 563-571. 1982 apud CAMPOS. F \& FURTADO. D.A. Matas Ciliares In: FURTADO, D. A.; KONIG, A. (Eds). Gestão integrada dos recursos hídricos. Campina Grande: Gráfica Agenda, 2008.

BRASIL. Resolução do Conama nº1, de 23 de janeiro de 1986. Dispõe sobre critérios básicos e diretrizes gerais para a avaliação de impacto ambiental. Brasília, 23 jan. 1986. Disponível em: https:// bit.ly/3nW8L0E. Acesso em: 07 jan. 2020.

BRASIL. Política Nacional do Meio Ambiente (PNMA), Lei No 6.938, de 31 de agosto de 1981. Disponível em: https://bit.ly/2XGbHDH. Acesso em: 25 ago. 2020.

BRUM, A. J. Modernização da agricultura: trigo e soja. Petrópolis: Vozes, 1988. 
CAMPOS, M. C.; TSUKAMOTO, R. Y. As principais correntes da agricultura não convencional. In: CARVAlHO, M. S. de. (Org.). Geografia, Meio-Ambiente e Desenvolvimento. Londrina: a Autora, p. 17-33, 2003 apud DALLANORA, I. B. e VALENTE, V. Organização socioespacial da localidade de Cerro Azul, no município de Pinhal Grande, RS: 1996-2006. Disciplinarum Scientia. Série: Ciências Humanas, Santa Maria, Santa Maria v. 15, n. 1, p. 17-32, 2014.

DECHEN, S. C.; TELLES, T. S.; GUIMARAES, M. F.; MARIA, I. C. Perdas e custos associados à erosão hídrica em função de taxas de cobertura do solo. Bragantia, v. 74, n. 2, 2015, p. 224-233. Disponível em: http://dx.doi.org/10.1590/1678-4499.0363. Acesso em: 15 jan. 2020.

EMATER/RS-ASCAR. Informativo Conjuntural/elaboração. Gerência de Planejamento. Núcleo de Informações e Análises. Porto Alegre: Emater/RS - Ascar, 2019. nº 1575 - 10 out. 2019. Disponível em: https://bit.ly/3CGSzER. Acesso em: 25 Jun. 2020.

FACCO, D. S.; BENEDETTI, A. C. P. ; FILHO, W. P. ; KAISER, E. A. \& DAL OSTO, J. V. Geotecnologias para monitoramento florestal no município de Nova Palma - Rio Grande Do Sul - BR. Revista Eletrônica em Gestão, Educação e Tecnologia Ambiental. Santa Maria, v. 20, n. 1, 2016, p. 417-426. Disponível em: https://bit.ly/3hWXMjN. Acesso em: 25 jul. 2020.

FACCO, D. S.; SOUZA, A. C. \& BENEDETTI, A.C.P. Geoprocessamento Algébrico para estudo da Dinâmica da Cobertura Florestal no município de Nova Palma (RS). Geoambiente On-Line: Revista eletrônica do curso de Geografia UFG/REJ, Jataí-GO: n 29 jul - dez, 2018. Disponível em: https:// doi.org/10.5216/revgeoamb.v0i29.47276. Acesso em: 12 ago. 2020.

FAO. Food and Agriculture Organization. The State of the World's Biodiversity for Food and Agriculture. Rome: FAO, 2019. Disponível em: https://bit.ly/3EKhlp9. Acesso em: 26 jul. 2020.

FURTADO, D. A.; KONIG A. Gestão Integrada de Recursos Hídricos. Campina Grande: Gráfica Agenda, 2008.

GONÇALVES, C. W. P. O desafio ambiental. Or. SADER.E. 3. ed. Rio de Janeiro: Record, 2012.

IBGE, Instituto Brasileiro de Geografia e Estatística. Brasília: Ministério do Planejamento, Censo da população 2010. Disponível em: https://bit.ly/39pn7hI. Acesso em: 26 jul. 2020.

LAGE, P. B. Impactos Ambientais gerados pela produção agrícola: uma revisão. Revista NAWA - 
UFAC e comunidade. v. 2, n. 2, 2017. Disponível em: https://bit.ly/39v1AnD. Acesso em: 27 jul. 2020.

LEFF, E. Epistemologia ambiental. 2. ed. São Paulo: Cortez, 2002.

MORENO, J. A. Clima do Rio Grande do Sul. Porto Alegre: Secretaria da Agricultura, 1961.

PIOVESAN, G.; AUSANI, G. Uso da terra na microbacia hidrográfica do Arroio Portela, no município de Nova Palma, RS. In: Disciplinarum Scientia. Série: Ciências Humanas, Santa Maria, v. 11, n. 1, p. 85-97, 2011.

ROSS, J. L. S. Geografia do Brasil. São Paulo: Edusp, 1995.

ROSSATO, P. S. O Sistema Termodinâmico do Clima Urbano de Nova Palma, RS: Contribuição ao Clima Urbano de Cidades Pequenas. Dissertação de Mestrado (Mestrado em Geografia). Universidade Federal de Santa Maria, 2010.

SILVA, C. E. M. Monocultura e conflito socioambiental. In: GESTA - UFMG, 2011. Disponível em: https:conflitosambientaismg.lcc.ufmg.br. Acesso em: 27 jan. 2019.

SILVA, J. A. da. \& BARROS, M. V. F. Uso do solo no manejo de bacias hidrográficas: o caso da bacia do ribeirão Cafezal - Londrina Paraná. In: CARVALHO, M. S. de (Org.). Geografia, meio ambiente e desenvolvimento. Paraná: Universidade Estadual de Londrina, p. 91-104, 2003.

SOUZA, M. C. S. A. \& GHILARDI, H. T. Recursos hídricos, agropecuária e sustentabilidade: desafios para uma visão ecológica do planeta. Revista Jurídica, Curitiba, v. 2, n. 47, 2017, p. 78-98. Disponível em: https://bit.ly/39pnzfU. Acesso em: 27 jul. 2020.

ZAMBERLAN, J. F. et al. Produção e manejo agrícola: impactos e desafios para sustentabilidade ambiental. Eng Sanit Ambient, Edição Especial, out/mai, p. 95-100, 2014. Disponível em: https:// bit.ly/3nRTJsS. Acesso em: 13 jul. 2020. 